\title{
Physical Basis of Prey Capture by Marine HETEROTROPHIC NANOFLAGELLATES
}

\author{
By Bruce C. Monger
}

$\mathrm{H}$ an important consumer group within pelagic foodwebs and play a vital role in cycling carbon and nitrogen in the world s oceans. Most primary production passes either directly or indirectly through heterotrophic nanoflagellates in the open ocean. In coastal environments. heterotrophic nanoflagellates are the dominant consumers of bacterial secondary production and the principal source of ammonium regeneration.

Most oceanic nanoflagellates have a relatively simple form and capture their heterotrophic and autotrophic picoplankton prey by chance contact with their cell surface as they swim randomly through the water. In theory. this feeding mechanism does not involve the structural complexity. intertaxonomic variability, or obvious behavioral complications of higher organisms. Consequently. it may be possible to understand a great deal about this ecologically important trophic interaction by viewing it from a purely physical perspective.

I directed my dissertation research toward understanding pres capture by marine nanotlagellates in terms of the physical forces arising between nanoflagellates and picoplankton prey as they approach one another. Basic concepts developed in the colloid literature were used to describe the prey capture process. A numerical model used to study colloidal interactions /Fitzpatrick. 1972 , was adapted to make predictions of nanoflagellate grazing rates. Model studies were formulated as a function of

BC Monger NASA. Coddurd Space Flehe Center. Code 971. Greenbeli. MD 20771. LSA: Ph.D. 1993. Department of Oceanography. Univerity of Hawani /Advisor: M.R. Landry. prey size. nanoflagellate swimming speed. and the balance between hydrodynamic. London-van der Waals. electrostatic. and solvation torces (Monger and Landry. 1990). In short. the relative strengths of attractive or repulsive molecular and hydrodynamic torces determine nanoflagellate grazing rates on picoplankton prey of a particular size (Fig. 1 ).

One of the more significant model predictions was that nanoflagellate grazing rates should increase approximately linearly with prey diameter-a relationship that conflicted with the quadratic dependency predicted by Fenchel (1982) and the cubic dependency interred by myself from data presented by Gonzalez. et al. (1990). Results from a series of feeding experiments aimed at resolving the discrepancy among the three relationships provided support for the linear size dependency Monger and Landr! 19911. A consequence of this result is that small size may not provide the extensive refuge from predation that was previously thought to exist.

The model inherently predicts the rate of pres contact and ignores portcontact rejection of prey. If selectise rejection of prey accurs 10 a ligniticant extent. a random contact model wich as the one I described would he unreliable for studying sysems that contain variable prey lypes. Tu test fur velection baned on fattor other than vize. ingestion rates were compared for an aplastidic chryomonad population teeding on a wide variety of prey $t y$ pes different yecies of live or hatt-killed bacteria. Syecherenews sp.. and lates microspheres of different i/e t Monger and Landry. 1942). Revalts indicated that postcontact pres rejection is probably not significant for this organism. Moreover, the higher precision associ- ated with the flow cytometric technique that was used to measure the grazing rates provided stronger statistical support for a linear prey-size dependency of grazing. Results from this work also suggested that highly motile bacteria may experience significantly higher predation losses due to an increase in the encounter rate with nanofiagellates resulting from their pronounced swimming behavior.

While the prediction regarding the relative prey size dependency of grazing is consistent with observation. the absolute magnitude of predicted grazing rates is generally low by a factor of 3 or + when compared with well-accepted literature values. Varying London-van der Waals and electrostatic double layer forces within reasonable natural limits caused modeled grazing rates to change by less than a factor of two. This led to a reconsideration of the possible importance of the hydrophobic interaction foree. This force $"$ as omitted in the initial model in an attempt to obtain the simplest possible model that could still make accurate predictions. Experiments devigned to meatsure directly the importance of the hydrophobic force now how that at modest increase in prey-uturface hydrophobicity. as revaled by hydrophohic interaction chromatography. can triple the rate at which pre! are ingested by nanoflagellate IB.C. Monger and M.R. Landry. unpublished whersations. These preliminary results sugegent that the hy drophobic force is a necessary component in the warall force expresion and offers a posvible explanation for the dincrepancy between model studies and obsertations of the absolute magnitude of nanotlagellate graking rates.

Entimating graling rate nn natural bacterial assemblages often involves experimental manipulation followed by 
A

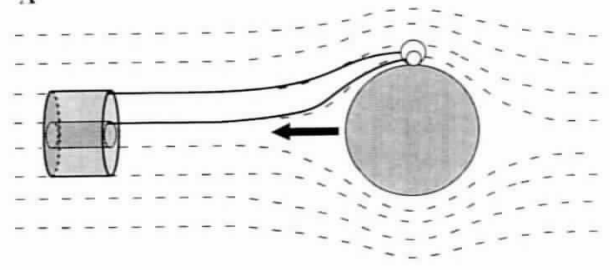

$$
\text { в }
$$

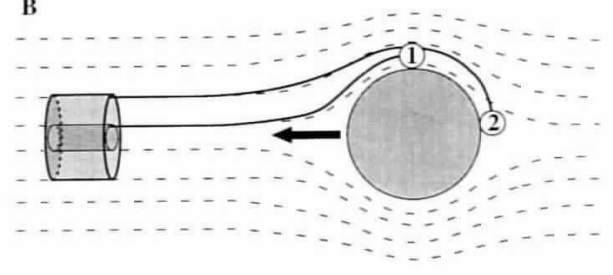

Figure 1: Representation of prey capture by an idealized nanoflagellate (shaded circle) feeding on picoplankton prey (open circles) of unequal size and same surface chemistry (A); and equal size but different surface chemistry (B). Prey types $I$ and 2 have surface chemistries that give rise, respectively, to small and large net attractive molecular forces between nanoflagellate and prey surfaces. Nanoflagellates swim with constant speed in the direction depicted by the arrow, and picoplankton are randomly distributed in space. Prey are captured when their centers approach within a prey radius of the nanoflagellate surface. Dashed and solid lines depict fluid streamlines and critical prey trajectories, respectively. A critical prey trajectory delineates the set of prey trajectories that result in capture from those that result in escape and is uniquely defined for prey of a given size and surface chemistry. Inner and outer cylinders represent the volumes of water cleared of prey per unit time for small and large prey $(\boldsymbol{A})$ or prey for similar size and surface types 1 and $2(B)$, respectively. Cylinder length is equal to distance a nanoflagellate swims per unit time. Cylinder radii are determined by the critical trajectories which, in turn, are a function of prey size and surface chemistry. measurement of small changes $(\sim 10 \%)$ in bacterial abundance. Measuring bacterial abundance with the precision necessary to measure such small changes reliably is generally not possible with traditional epifluorescent direct counting methods. Consequently, I developed a fluorescent staining technique that, in conjunction with flow cytometric methods, allows rapid, precise, and unambiguous enumeration of marine bacteria (Monger and Landry, 1993). This method is currently being used in field studies where methods to measure bacterial motility and hydrophobicity and nanoflagellate grazing rates require very precise measurement of bacterial abundance.

Others have shown that changes in nutrient availability can alter bacterial size, motility, and hydrophobicity which in turn affects the specific growth rate of bacteria. On the basis of my dissertation research, it now seems likely that predation rates on bacteria will also be affected by nutrient status. I am currently doing postdoctoral research on picoplankton dynamics along a nutrient gradient from the perspective of changes in picoplankton size, motility, and hydrophobicity.

\section{References}

Fenchel, T., 1982: Ecology of heterotrophic microflagellates. I. Some important forms and their functional morphology. Mar. Ecol. Prog. Ser., 8, 211-223.

Fitzpatrick, J.A., 1972: Mechanisms of particle capture in water filtration. Ph.D. thesis. Harvard University.

González, J.M.. E.B. Sherr and B.F. Sherr, 1990: Size-selective grazing on bacteria by natural assemblages of estuarine flagellates and ciliates. Appl. Environ. Microbiol., 56, 583-589.

Monger, B.C. and M.R. Landry, 1990: Direct-interception feeding by marine zooflagellates: the importance of surface and hydrodynamic forces. Mar. Ecol. Prog. Ser., 65 , $123-140$

and M.R. Landry, 1991: Dependency of prey size on grazing by free-living marine zooflagellates. Mar. Ecol. Prog. Ser., 74, 239-248.

- and M.R. Landry, 1992: Size-selective grazing by heterotrophic nanoflagellates: an analysis using live-stained bacteria and dual-beam flow cytometry. Arch. Hydrobiol. Beih., 37, 173-185.

- and M.R. Landry, 1993: Flow cytometric analysis of marine bacteria with Hoechst 33342. Appl. Environ. Microbiol., 59, 905-911. 